\title{
Reply to commentary to "Decellularized dermal strip as a suburethral sling in a rat model of stress urinary incontinence" by Ajay K. Singla
}

\author{
Abdol-Mohammad Kajbafzadeh ${ }^{1}$ Sarah Mozafarpour ${ }^{1}$
}

Received: 9 August 2015 / Accepted: 19 August 2015 / Published online: 2 September 2015

(C) Springer Science+Business Media Dordrecht 2015

\section{Editor,}

We appreciate the comments of Ajay K. Singla on our manuscript entitled: Decellularized dermal strip as a suburethral sling in a rat model of stress urinary incontinence [1].

Surgical treatment of stress urinary incontinence remains a challenge worldwide, and the search for the optimal sling material is still ongoing. The aim of this animal study was to investigate the biocompatibility of decellularized dermal graft as a less costly and more widely available material for suburethral sling.

Small intestinal submucosa needs special tissue handling technique to make a multilayer configuration [2]. There are limitations in using this material in large-scale preparations, and the physical characteristics are also location dependent [3]. Moreover, the durability of this material is not assured in human long-term studies [4].

In our country, the ministry of health requires that every new material first be tested in animal models and subsequently in limited number of human cases. Only after these steps are performed, the ethical permit is issued for large-scale clinical testing. In our research center, in order to produce acellular human dermal matrix, we conduct different modalities to ensure appropriateness of material such as several staining methods, scanning electron microscopy, DAPI staining, cytotoxicity testing, biomechanical testing and extensive quality control studies including bacterial and viral

Abdol-Mohammad Kajbafzadeh

kajbafzd@sina.tums.ac.ir

1 Pediatric Urology Research Center, Section of Tissue Engineering and Stem Cells Therapy, Children's Center of Excellence, Tehran University of Medical Sciences, Tehran, Iran (IRI) contamination testing. We hypothesize that the unique constellation of these examinations reduces the risk of contamination with acellular dermal matrix compared to other materials such as cadaveric fascia. Needless to say, randomized clinical trials are warranted to compare the efficacy and the risk of contamination.

Various factors contribute to the personal preference of surgeons in choosing the material; however, there is no consensus about the safest material and many questions remain unanswered. We consider this study as the initial step to evaluate the in vivo behavior of decellularized dermal graft rather than introducing it as a xenograft. We used a decellularization technique to ensure that the dermal strip was to the maximum extent possible cell free in order to minimize the risk of immunogenic reaction. It is worth to mention that we do not use freeze drying technique in the tissue preparation process, which is evidently damaging.

\section{References}

1. Kajbafzadeh AM, Mozafarpour S, Ladi Seyedian SS, Khorramirouz R, Nasser Hojjati H (2015) Decellularized dermal strip as a suburethral sling in a rat model of stress urinary incontinence. Int Urol Nephrol 47(8):1303-1310

2. Hakim L, De Ridder D, Van der Aa F (2015) Slings for urinary incontinence and the application of cell-based therapy. Adv Drug Deliv Rev 82-83:22-30

3. Raghavan D, Kropp BP, Lin HK, Zhang Y, Cowan R, Madihally SV (2005) Physical characteristics of small intestinal submucosa scaffolds are location-dependent. J Biomed Mater Res A 73(1):90-96

4. Siracusano S, Ciciliato S, Lampropoulou N, Cucchi A, Visalli F, Talamini R (2011) Porcine small intestinal submucosa implant in pubovaginal sling procedure on 48 consecutive patients: long-term results. Eur J Obstet Gynecol Reprod Biol 158(2):350-353 